\title{
Preventive dentofacial orthopedic treatment of childhood apnea/hypopnea syndrome?
}

\author{
M. Guibert ${ }^{1,3}$, R. Garcia ${ }^{2,3}$ \\ 1 Lecturer, Certificate course in Odontostomatologic Treatment of Obstructive Sleep Apnea \\ Syndrome, Paris 7 University, Paris (France) - Member of the French Society of Dental Sleep \\ Medicine \\ 2 Professor of Odontology, Paris 7 University, Paris (France) - Director, Certificate course in \\ Odontostomatologic Treatment of Obstructive Sleep Apnea Syndrome-Vice-President of the \\ French Society of Dental Sleep Medicine \\ ${ }^{3}$ Specialist in Dentofacial Orthopedics
}

ABSTRACT

Adult and childhood obstructive sleep apnea/hypopnea syndromes (OSAHS) differ greatly in pathophysiology and semiology.

Management of childhood OSAHS is specific.

Dentofacial orthopedics should screen for OSAHS, and refer patients to a multidisciplinary team.

Although there is no facial typology specific to OSAHS, maxillary endognathy, mandibular retrognathy and long-face syndrome are carry extra risk. Early adapted treatment should reduce this risk.

\section{KEYWORDS}

Apnea, OSAHS, DFO, maxillary expansion

The characteristics of childhood obstructive apnea syndrome are such as to require specific study 2,19 .

The first concerns obstruction: apart- from sleep apnea of central origin, childhood sleep apnea is due to excessive oropharyngeal contents (tonsils, adenoid vegetations) rather than deficient airway opening related to parietal depression.

Treatment of these young patients is thus mostly surgical: tonsillectomy.

However, a certain number of patients are non-responders to surgery, suggesting that the problem may lie more with the container than the contents of the oro- pharynx. Thus the hypothesis of an architectural phenotype specific to this symptom arose $e^{17,24,32}$.

In this context, dentofacial orthopedics (DFO) comes into its own as a preventive strategy against onset of apnea syndrome, countering the skeletal conditions underlying the respiratory obstruction.

The present study aimed to highlight the differences between childhood and adult apnea syndrome in terms of pathophysiology, semiology and treatment. It is illustrated by 3 typical cases confirming the usefulness of DFO in at-risk patients.

Address for correspondence:

Mireille Guibert

57, Quai Gabriel Péri - 83500 La-Seyne-sur-Mer

France

E-mail: mireille.guibert@wanadoo.fr

Article received: 20-02-2015. Accepted for publication: 03-03-2015.

This is an Open Access article distributed under the terms of the Creative Commons Attribution License (http://creativecommons.org/licenses/by/4.0), which permits unrestricted use, distribution, and reproduction in any medium, provided the original work is properly cited. 


\section{PATHOPHYSIOLOGY OF CHILDHOOD OBSTRUCTIVE APNEA ${ }^{11,12,27}$}

The airway allowing inbreathed air to reach the lungs is sometimes an obstacle course.

From the threshold of the nostrils, the air passes through the nasal cavities, the skeletal walls of which are non-depressible. Likewise, at the tracheal end, the cartilaginous architecture enables the tubular lumen to remain open.

Thus, if there are no anatomic abnormalities, obstruction must lie between these two structures.

It is thus in the pharynx, and more precisely in the oropharynx, that airflow may be obstructed due to the depressible nature of the collapsible musculo-membranous walls $s^{4,14}$. It is here that airflow may be obstructed, inducing either apnea (blocked flow) or hypopnea (reduced flow). Turbulence here leads to snoring by causing the soft palate and uvula to vibrate.

This is the usual scenario in adults: airflow interrupted by pharyngeal wall obturation (fig. 1).

Two etiologies contribute to this interruption:

- reduced pharyngeal dilator contraction from the initiation of the in-breath (diaphragm contraction) $4,5,14,19$;

- reduced pharyngeal lumen due to lipid infiltration, often, related to obesity or age 20,32 .

In children, nasal cavity bone anatomy and tracheal cartilage anatomy are the same as in adults. The airway, however, may be obstructed at different levels. Excessive volume in the medial and inferior turbinates, adenoid vegetations and/or tonsils causes airway obstruction (fig. 2).
This difference in pathophysiology goes a long way to explaining the semiological differences between children and adults, which are such as to warrant speaking of two different syndromes ${ }^{5,12}$.

In adults, males are more affected than females up to the menopause, whereas there is no such sex-related difference in children 3,4,10,13,19.

Snoring with pauses is an alarm signal and characteristic of adult apnea syndrome, whereas it is less frequent and does not involve pauses in children $^{4,21}$

Obesity is a well-known cofactor in adult apnea ${ }^{1,6,13,31}$, so much so that it is sometimes referred to as Pickwick syndrome $^{8}$, in reference to Dickens' character; but it is rare in children ${ }^{7,19}$.

Nycturia is frequent in adults, and exceptional in children ${ }^{15}$.

Daytime somnolence is typical of adult apnea, whereas hyperactivity and attention deficit at school are major signs in children ${ }^{12}$.

The frequency of nocturnal events differs greatly between adults and children: in adults, apnea is diagnosed for apnea/hypopnea index (AHI) $\geq 5$, while in children $\mathrm{AHI} \geq 1$ is considered pathological, requiring adapted management ${ }^{27}$.

Facial pattern is often seen as a cofactor in apnea syndrome, but no specific typology currently characterizes syndromic or at-risk patients $3,9,12,19$.

Nevertheless, dysmorphism involving an anterior position of the hyoid bone on which the base of the tongue inserts is considered a risk factor for syndrome onset ${ }^{29}$. 


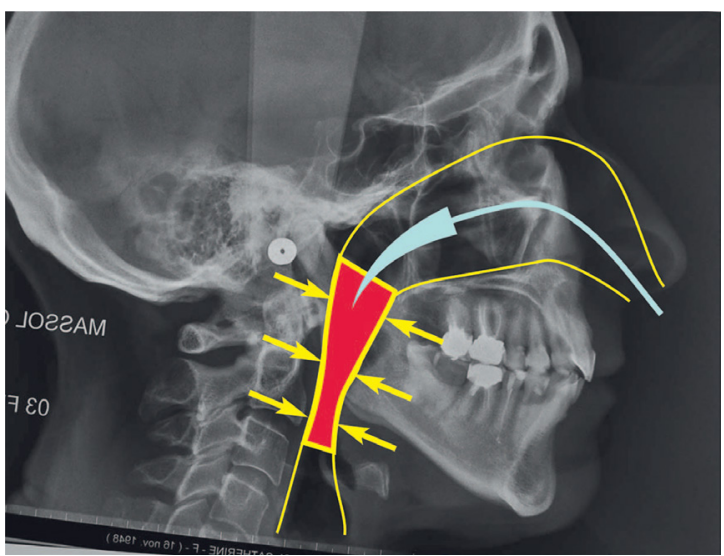

Figure 1

In adults, airway obturation is related to oropharyngeal parietal depressibility.

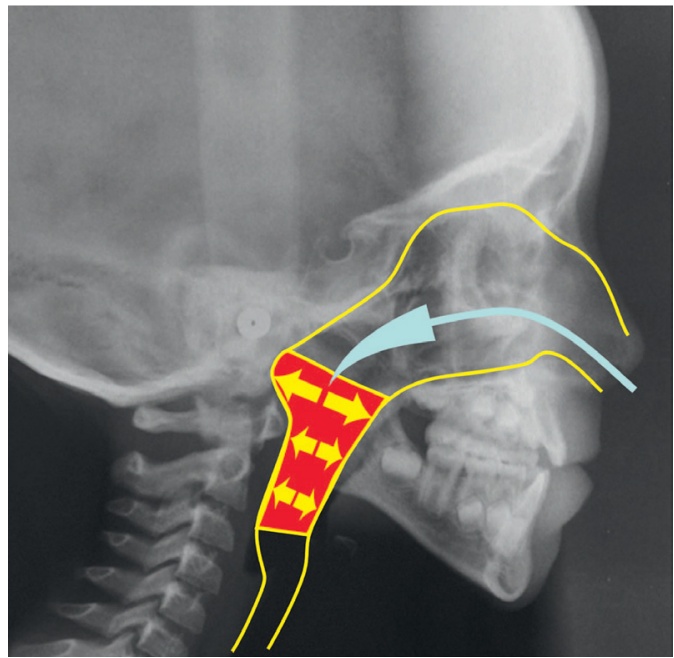

Figure 2

In children, airway obturation is related to excessive adenotonsillar volume.

\section{MANAGEMENT OF CHILDHOOD OBSTRUCTIVE APNEA ${ }^{27}$}

In case of apnea confirmed on polysomnography and palatine and/ or pharyngeal tonsillar hypertrophy found on ENT examination, tonsillectomy id indicated ${ }^{23,26}$.

It is reported to be effective in $80 \%$ to $90 \%$ of cases, but is not always sufficient to resolve apnea ${ }^{17}$.

Several authors ${ }^{16,23}$ have reported a facial phenotype associated with nonresponse to tonsillectomy: mandibular retrognathy ${ }^{22}$, maxillary endognathy ${ }^{18,33}$ and/or facial ${ }^{22}$ are reported as risk factors for apnea syndrome.

In this context, Peltomäki's study ${ }^{22}$ deserves particular attention. Following the work of Bar and of Goldstein, it reported the impact of tonsillectomy on growth hormone secretion in young apnea sufferers. By acting specifically on condylar cartilage, reduced secretion may induce mandibular retrognathy and/or facial hyperdivergence.
It is therefore indispensable to analyze respiration, so as to guide treatment in case of suspected apnea syndrome.

It is here that DFO has a preventive role to play. Any means of anteriorizing the tongue base is contributive. Three representative cases illustrate our preventive approach to tongue positioning.

\section{Maxillary expansion}

In case of endognathy and/or dental arch contraction with uni- or bi-lateral occlusion inversion and $\mathrm{AHI}>1$, maxillary expansion is indicated.

Harmonic medial palatine suture shows long-lasting action: synfibrosis at a very young age, progressively developing into synarthrosis, which no; longer responds to mechanical orthodontic activation. Expansion then:

- increases the volume of the "tongue box" by transverse action; 


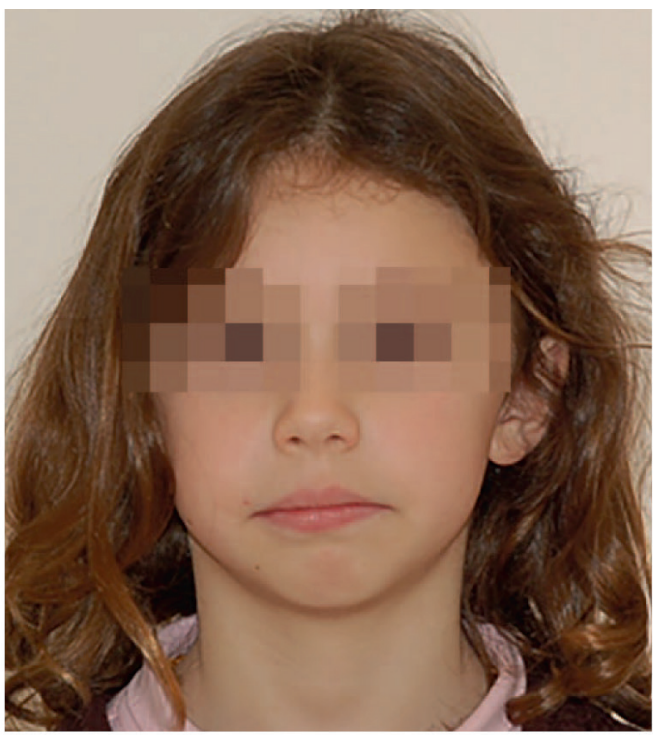

a

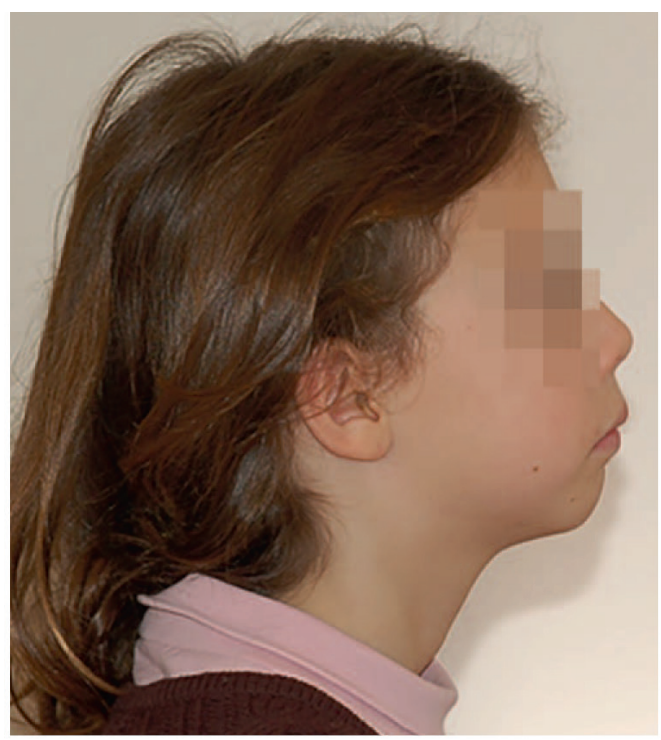

b

Figure $3 a$

Jully C. a) Jully, aged 7 years, presented with asymmetric long face, and b) convex profile associated with permanent mandibular contraction.

- helps elevate and anteriorize the tongue, enhancing its morphogenetic role.

The expander may be fitted up to 15 years of age, but the earlier the better the results in terms of occlusion and function.

The case of Jully C. (fig. 3), aged 7, perfectly illustrates this treatment protocol.

Sleep recording confirmed obstructive apnea syndrome, with $\mathrm{AHI}=5$.

Adenotonsillectomy was followed 2 months later by maxillary expansion; $\mathrm{AHI}$ fell from 5 to 0 .

This protocol perfectly illustrates Peltomäki's theory ${ }^{22}$ of facial growth "normalization" by reorienting maxillary growth.

\section{"Stimulation" of mandibular growth}

OSAS prevention is based on a simple principle: increase tongue habitat volume by transverse and/or sagittal action. Any such intervention will provide preventive benefit.

Correction of skeletal class II mandibular retrognathy is a prime example of such prevention.

\section{Orthodontic treatment without extraction}

The case of Sophie B. (fig. 4) illustrates this approach.

With mandibular skeletal class II $\left(\mathrm{SNB}=72^{\circ}\right)$ and facial hypodivergence, 


\section{ENT PROBLEMS}

Does your child have:

$\begin{array}{lll}\text { difficulty breathing } & 0 \text { yes } & 0 \text { no } \\ \text { frequent head-colds } & X \text { yes } & 0 \text { no } \\ \text { frequent ear-ache } & 0 \text { yes } & 0 \text { no } \\ \text { pharyngitis } & X \text { yes } & 0 \text { no } \\ \text { rhinopharyngitis } & X \text { yes } & 0 \text { no }\end{array}$

Has your child had surgical removal of :

$\begin{array}{lll}\text { tonsils } & 0 \text { yes } & 0 \text { no } \\ \text { adenoids } & 0 \text { yes } & 0 \text { no }\end{array}$

Does your child show the following signs:

$\begin{array}{lll}\text { mouth open in daytime } & \text { X yes } & 0 \text { no } \\ \text { sucking thumb, fingers, comforter } & 0 \text { yes } & 0 \text { no } \\ \text { sucking lower lip } & 0 \text { yes } & 0 \text { no } \\ \text { sleeping mouth open } & \text { X yes } & 0 \text { no } \\ \text { snoring } & \text { X yes } & 0 \text { no } \\ \text { rings under the eyes } & 0 \text { yes } & 0 \text { no } \\ \text { night sweats } & \text { X yes } & 0 \text { no } \\ \text { difficulty waking up } & \text { X yes } & 0 \text { no } \\ \text { bed-wetting } & 0 \text { yes } & 0 \text { no } \\ \text { enuresis } & 0 \text { yes } & 0 \text { no } \\ \text { chapped lips } & 0 \text { yes } & 0 \text { no } \\ \text { frequent nightmares } & \text { X yes } & 0 \text { no } \\ \text { sleep-walking } & 0 \text { yes } & 0 \text { no } \\ \text { sleep-talking } & 0 \text { yes } & 0 \text { no } \\ \text { saliva stains on pillow } & X \text { yes } & 0 \text { no } \\ \text { frequent waking up at night } & 0 \text { yes } & 0 \text { no } \\ \text { sleep apnea } & 0 \text { yes } & 0 \text { no }\end{array}$

Figure $3 b$

Jully C. b) Questionnaire discloses frequent ENT infections; oral breathing and snoring; frequent nightmares and difficulty waking up; hyperactivity and loss of concentration at school.

the patient's facial pattern showed all the characteristics of this type of malocclusion.

Documentary analysis of 2 years' multi-bracket treatment highlighted the impact on facial growth.
Attention should be paid to two elements:

- facial hypodivergence allows accelerated mandibular growth;

- anterior supra-occlusion must be resolved ahead of mandibular advancement. 

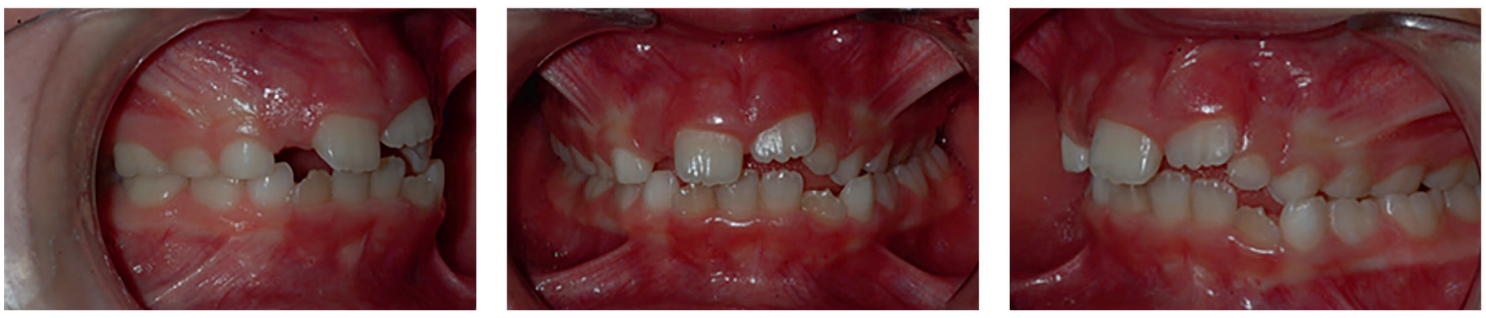

C
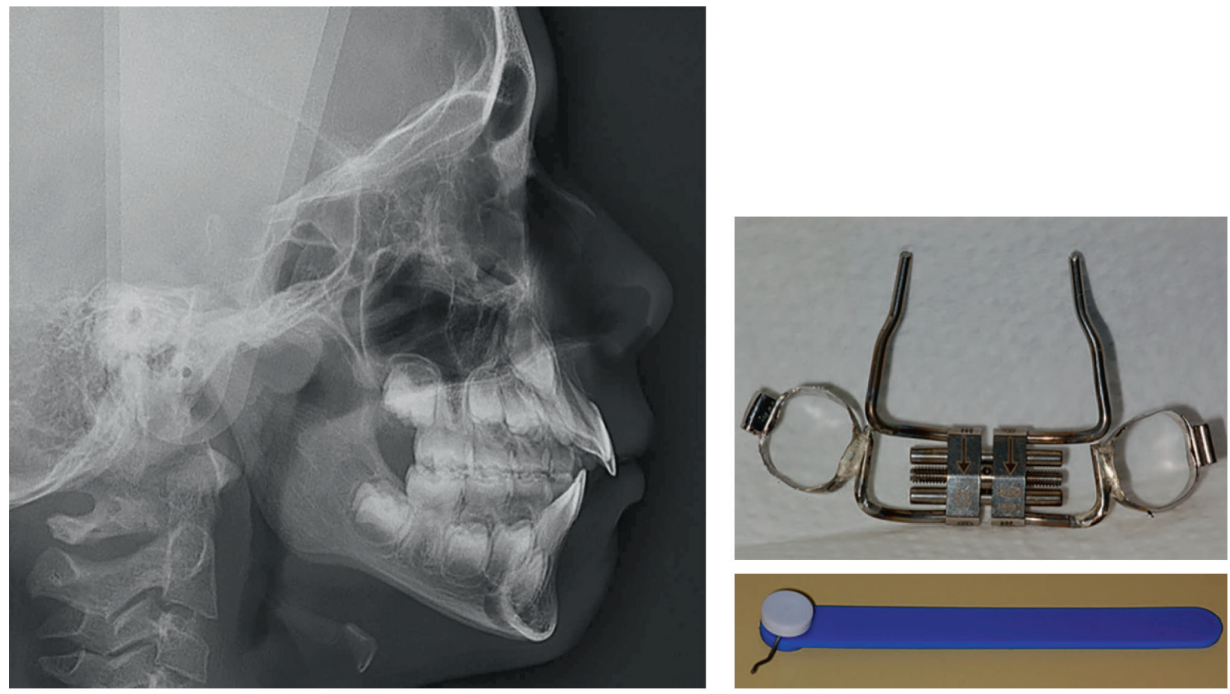

d

e
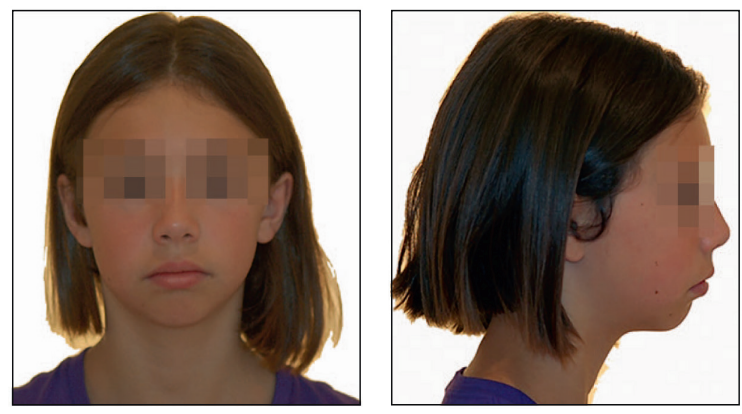

f

Figure 3c

Jully C. c) Intraoral examination finds asymmetric class II malocclusion with left lateral occlusion inversion and mandibular and maxillary incisor crowding. d) Lateral teleradiograph showing mandibular retrognathy $\left(S N B=74^{\circ}\right)$ and facial hyperdivergence $\left(F M A=30^{\circ}\right)$. e) Treatment comprised tonsillectomy followed by maxillary expansion. the expander was given a quarter turn each morning and evening: i.e., $0.5 \mathrm{~mm}$ per day. After transverse correction, the device was removed at 6 months. f) Three months after this phase, obstructive apnea had completely resolved. The face was well-balanced, without mandibular contraction. 

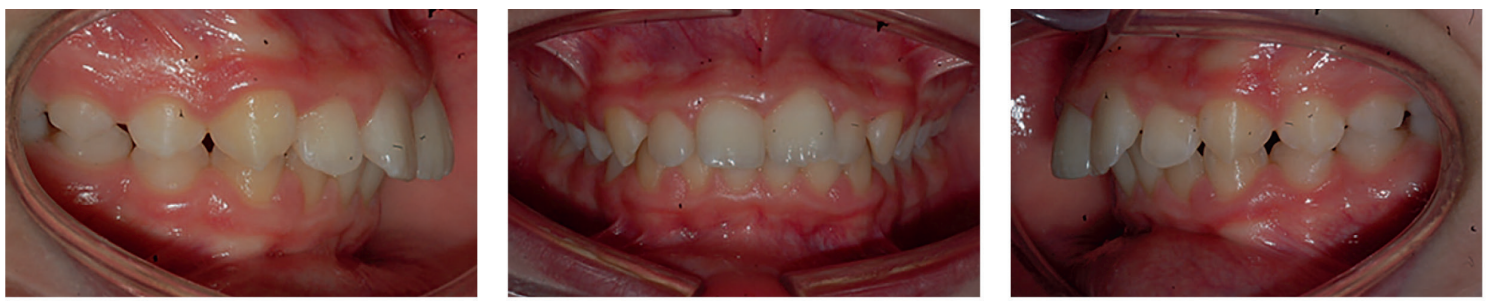

g

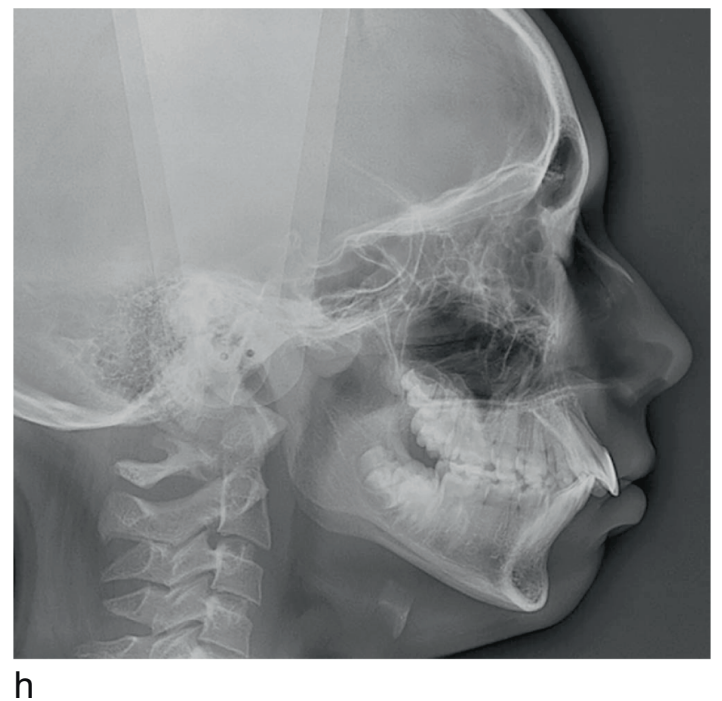

Figure $3 g$

Jully C. g) Complete correction of lateral and medial occlusion inversion. h) Skeletally, facial divergence was reduced (FMA reduced from $30^{\circ}$ to $27^{\circ}$ ). Mandibular sagittal growth reduced skeletal class II (SNB increased from $74^{\circ}$ to $\left.77^{\circ}\right)$.

Mandibular growth response to orthodontic mechanical stimulation in this kind of facial pattern achieves mandibular lengthening, opening the airway at the base of the tongue.

\section{Orthodontic treatment with extraction}

There has recently been a certain polemic, notably on the Internet, concerning dental (premolar) extraction and onset of OSAS. To date, no scientific studies have demonstrated a causal relation between extraction and onset of sleep apnea; quite the contrary ${ }^{28}$. It may simply be that reduced tongue volume due to incisor-canine regression may in- duce distal displacement of the tongue. Examples could be correction of biproalveolism or of overjet by anterior maxillary retraction to compensate for mandibular retrognathy. Alternatively, second mandibular premolars might be extracted if progressing totally lingually, which is a particular case but not especially rare, to make room for more anterior positioning of the tongue.

Also, skeletal class II with hyperdivergent face may require extractions to achieve vertical control in the molar region and allow effective mandibular response to sagittal skeletal correction. 

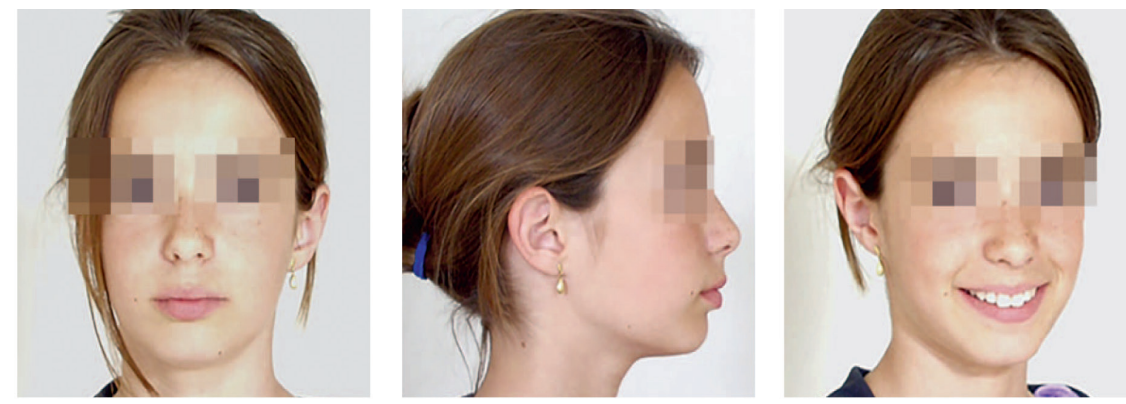

a
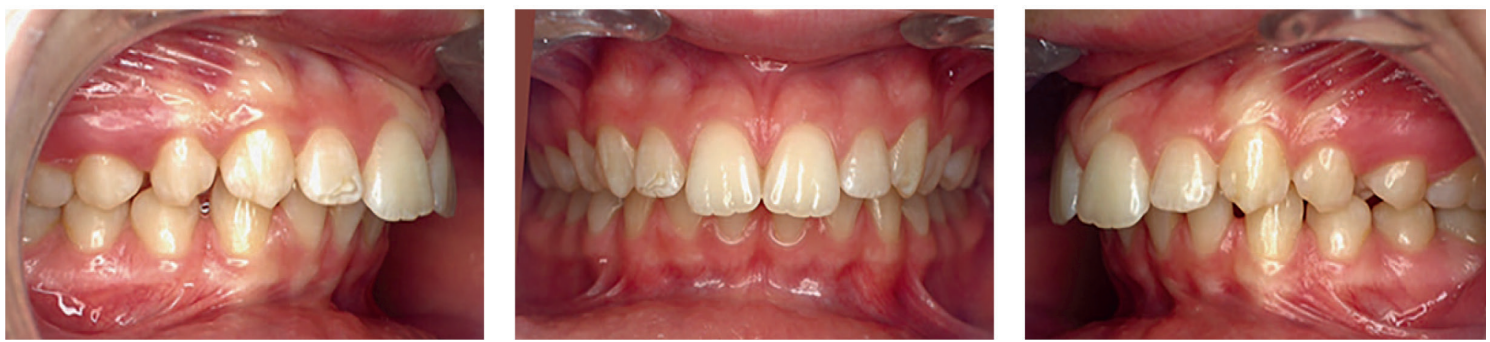

b

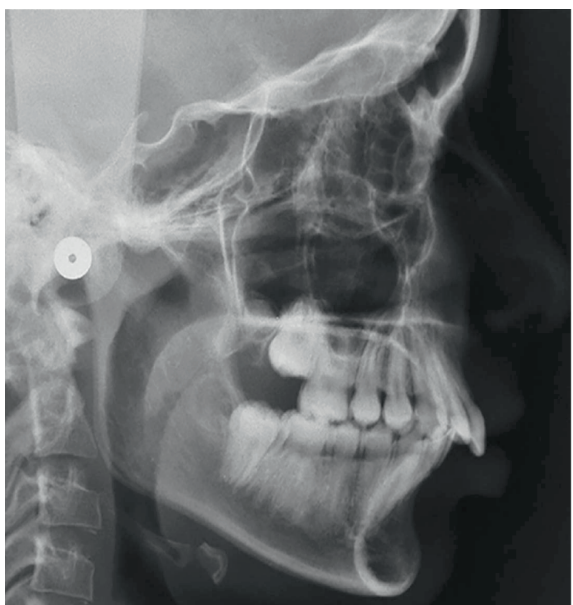

C

Figure $4 a, b, c$

Sophie B. a) Sophie, aged 11 years, presented with a symmetric oval face and convex profile with retruding chin. The lip-chin groove was deep. In smiling, the maxillary incisors projected forward - whence her nickname of "Little Rabbit", which was a ^prime reason for consultation. b) Intraoral examination found Angle class I division 1 malocclusion with $10 \mathrm{~mm}$ overjet associated with $6 \mathrm{~mm}$ anterior supra-occlusion. c) Lateral teleradiograph, showing skeletal class II $\left(A N B=10^{\circ}\right)$, mandibular retrognathy $\left(S N B=72^{\circ}\right)$ and hypodivergence $\left(F M A=19^{\circ}\right)$. 

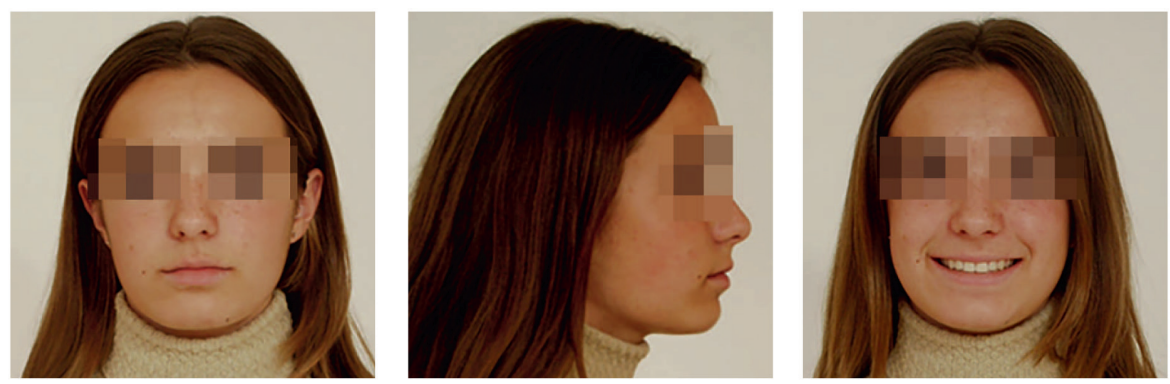

d
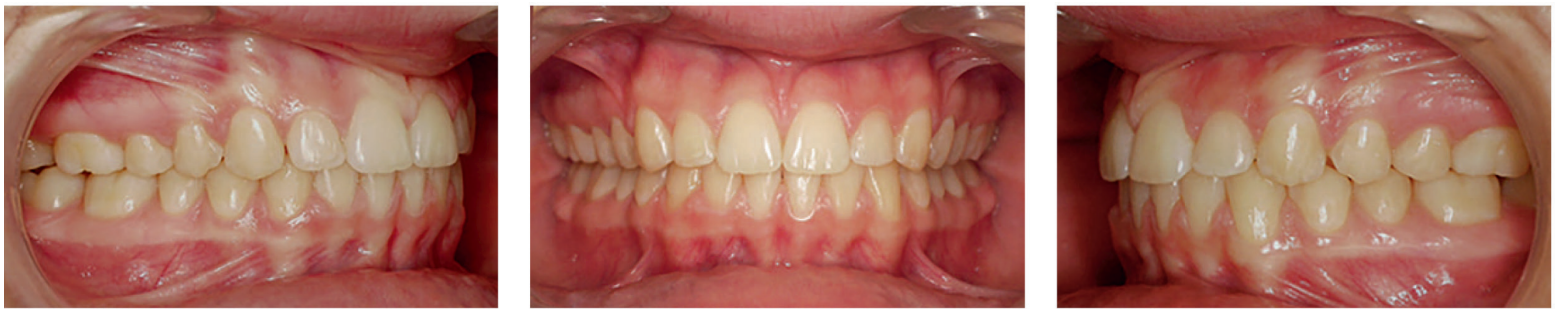

e

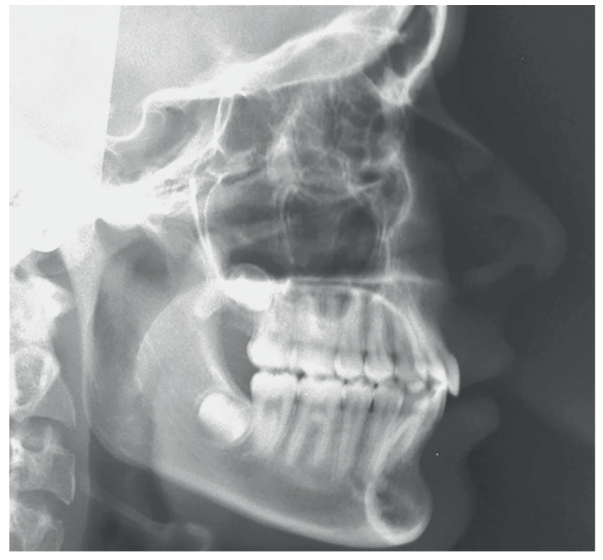

f

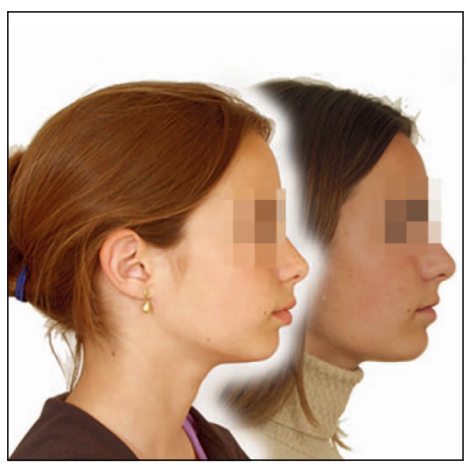

g

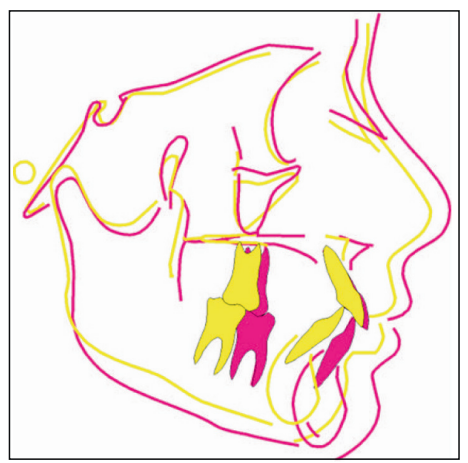

$\mathrm{h}$

Figure $4 d$

Sophie B. d) After 2 years' treatment, the profile is harmonious. The lip-chin groove has lessened. The smile is pleasant, with normal maxillary incisor exposure. e) Occlusion shows complete correction of molar and canine class II, and of the anterior supra-occlusion. f) Skeletally, the vertical is under control. Mandibular sagittal growth has reduced the skeletal class II (SNB increased from $74^{\circ}$ to $\left.78^{\circ}\right)$. g) Comparison of profiles shows the morphologic correction of the inferior face. h) Cephalometric superimposition shows mandibular growth, correcting sagittal relations in the skeletal bases by increasing tongue-box volume. 

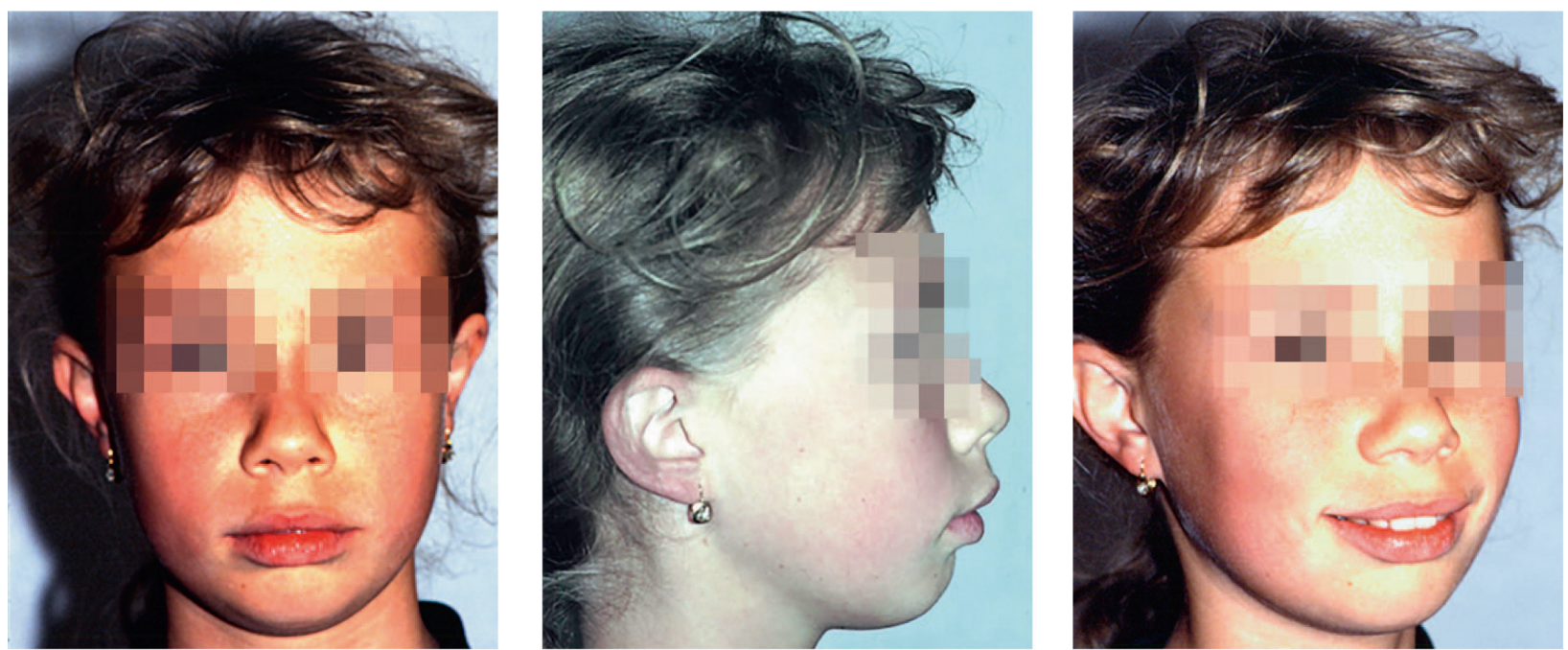

a

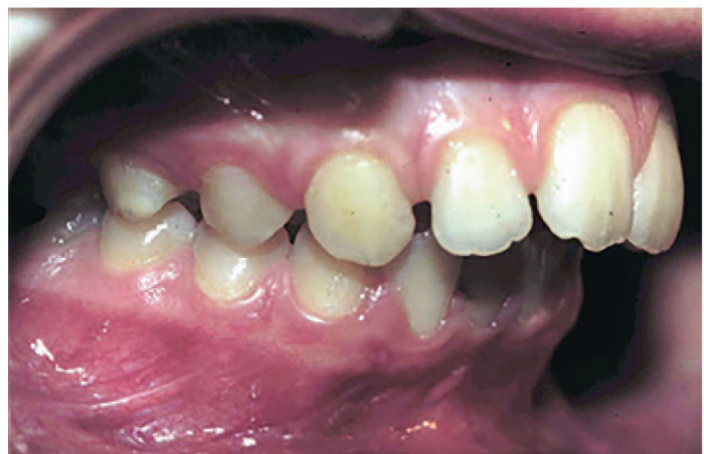

b

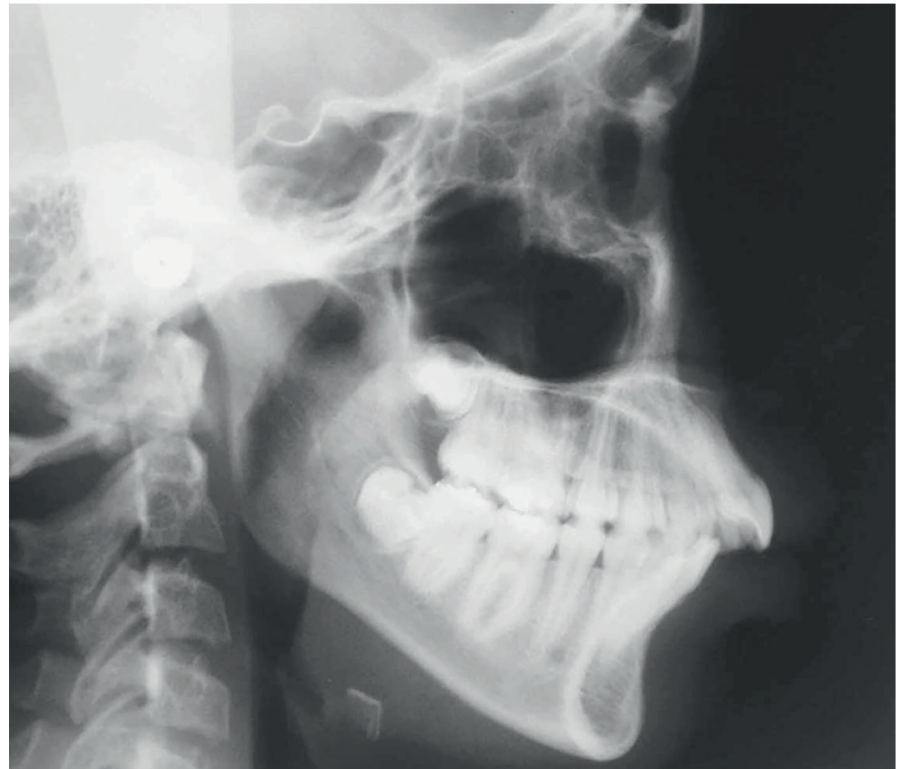

C

Figure $5 a, b, c$

Virginie M. a) Virginie, aged 12 years, presented with a symmetrical face and convex profile with shallow lip-chin groove. b) Intraoral examination found Angle class I/ division I malocclusion with $11 \mathrm{~mm}$ overjet and $4 \mathrm{~mm}$ anterior supra-occlusion. c) Lateral teleradiograph showing skeletal class // $\left(A N B=10^{\circ}\right)$, mandibular retrognathy $\left(S N B=73^{\circ}\right)$ and hyperdivergence (FMA $\left.=31^{\circ}\right)$. 

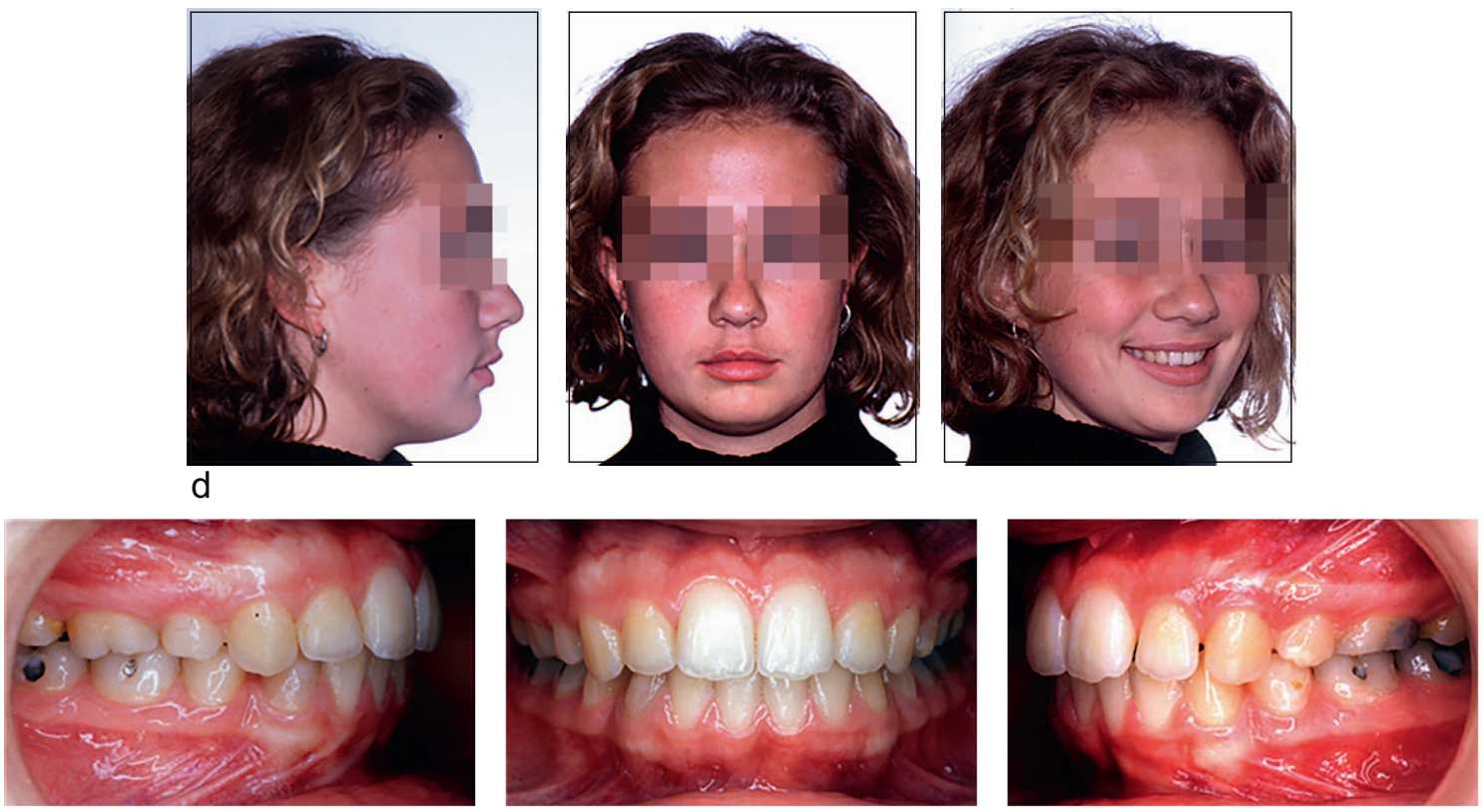

e

Figure $5 d$, e

Virginie M. d) After two and a half years' treatment, the profile is harmonious. Lip relations are ideal. The smile is perfectly positioned. e) Occlusion shows total correction of molar-canine class II. Likewise, anterior supra-occlusion has been corrected.

Such was the case for Virginie M. (fig. 5), who presented with a convex face and retracted chin and facial hyperdivergence $\left(\mathrm{FMA}=31^{\circ}\right)$; the skeletal class II $\left(\mathrm{ANB}=10^{\circ}\right)$ was related to mandibular retrognathy $\left(S N B=73^{\circ}\right)$.

After two and a half years' multibracket treatment and extraction of 14 ,
2435 and 45, analysis of end-of-treatment data highlighted the impact on facial growth.

Molar vertical control was essential to ensuring horizontal growth. Otherwise, mandibular opening would counter the objective by pushing the base of the tongue back.

\section{CONCLUSION}

Airway obstruction is caused by depression of the muscular walls of the oropharynx in adults, whereas in children it is mostly "excess contents" (tonsils, adenoid vegetations) that induces apnea.
It should be borne in mind that respiratory flow is proportional to airway area raised to the power 4 (Bernouilli's law). Thus a $2 \mathrm{~mm}^{2}$ reduction in area results in a $15 \%$ reduction in inspiration volume over the affected period. 

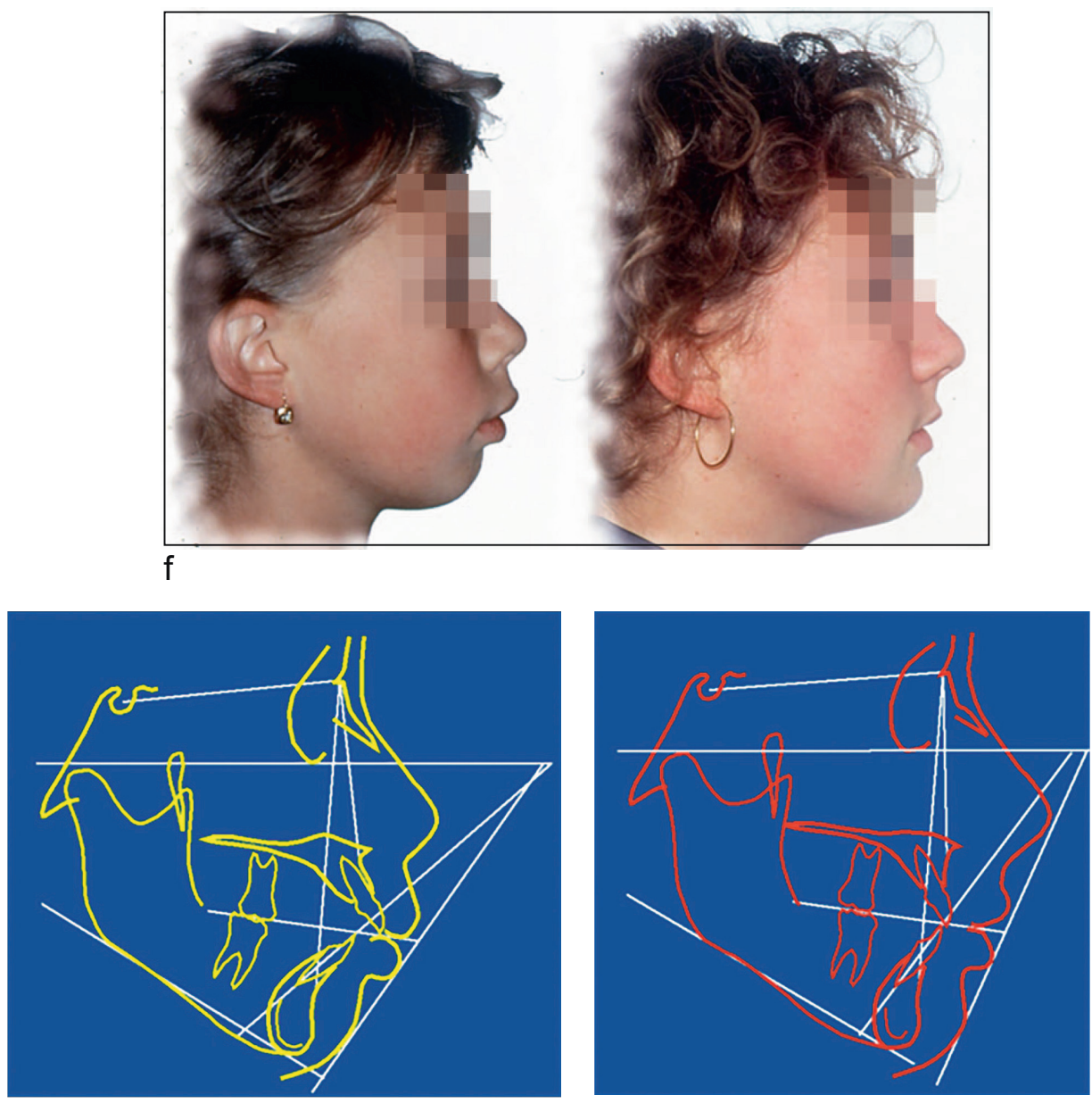

9

Figure $5 f, g$

Virginie M. f) Profile comparison shows morphologic correction of the lower face. f) Skeletally, facial divergence is totally controlled $\left(F M A=28^{\circ}\right)$. Sagittal mandibular growth has reduced the skeletal class II (ANB reduced from $10^{\circ}$ to $4^{\circ}$ ) thanks to significant mandibular growth (SNB increased from $73^{\circ}$ to $81^{\circ} \%$ g) Cephalographic comparison shows mandibular growth.

Dentofacial orthopedics, over and above its functional and esthetic objectives, should take account of the pathognomic potential of the child's facial pattern. While there is no specific associated pattern, mandibular retrognathy, maxillary endognathy and/or facial hyperdivergence are risk factors for apnea syndrome. Orthodontic treatment should be as early as possible, to optimize skeletal results.

Treatment should achieve absolute control of occlusion and mandibular plane orientation, as downward and backward tilt inevitably narrows the airway at the base of the tongue, promoting onset of apnea syndrome.

Conflicts of interest: The authors declare no conflicts of interest. 


\section{REFERENCES}

1. Ahmed $M H$, Byrne CD. Obstructive sleep apnea syndrome and fatty liver: Association or causal link? World J Gastroenterol 2010;16(34):4243-52.

2. Arnulf I, Derenne J-P. Le syndrome d'apnées du sommeil. Médecine/sciences. 1999;15:807-14.

3. American Academy of sleep medecine. Sleep-related breathing disorders in adults: Recommendations for syndrome definition and measurement techniques in clinical research. Sleep. 1999;22(5):667-89.

4. Billiard M, Dauvilliers Y. Hypersomnies. EMC-Neurol. 2004;Article(17-025-B-15):1-16.

5. Bonete D, Pons Y, Petitjean T, Beaute D, Nottet J-B, Suc B. Syndrome d'apnées obstructives du sommeil de l'adulte. EMC-Medecine buccale. 2009;Article(28-355-M-10):1-20.

6. Bonsignore MR, Borel A-L, Machan E, Grunstein R. Sleep apnoea and metabolic dysfunction. Eur Respir Rev Off J Eur Respir Soc. 2013;22(129):353-64.

7. Bonsignore MR, McNicholas WT, Montserrat JM, Eckel J. Adipose tissue in obesity and obstructive sleep apnoea. Eur Respir J. 2012;39(3):746-67.

8. Burwell CS, Robin ED, Whaley RD, Bickelman AG. Extreme obesity associated with alveolar hypoventilation: a pickwickian syndrome. American Journal of Medecine. 1956;21:811.

9. Carvalho FR, Lentini-Oliveira D, Machado MAC, Prado GF, Prado LBF, Saconato H. Oral appliances and functional orthopaedic appliances for obstructive sleep apnoea in children. Cochran Database Syst Rev. 2000;23:1-6.

10. Casteby Ware J, McBrayer RH, Scott JA. Influence of sexand age on duration and frequency of sleep apnea. Sleep. 2007:issue 2.

11. Cohen-Levy J, Garcia R, Pételle B, Fleury B. Traitement du syndrome d'apnées obstructives du sommeil de l'adulte par orthèse d'avancée mandibulaire : actualisation des connaissances. Int Orthod. 2009;3(7):287-304.

12. Escourrou P, Meslier N, Raffestin B, et al. Quelle approche clinique et quelle procédure diagnostique pour le SAHOS ? Rev. Mal. Respir. 2010;27:S115-23.

13. Escourrou P,Roisman GL. Epidémiologie du syndrome d'apnées-hypopnées obstructives du sommeil de l'adulte et de ses complications. Médecine Sommeil. 2010;7(4):119-28.

14. Fleury B. Musculature pharyngée et syndrome d'apnées obstructives du sommeil (SAOS). Rev Mal Respir. 2000;17:3S15-20.

15. Gagnadoux F, Meurice J-C. Recommandations pour la pratique clinique du syndrome d'apnées hypopnées obstructives du sommeil de l'adulte. Rev Mal Respir. 2010 Oct;27 supplément 3.

16. Garcia R, Fauquet Roure C, Fleury B, Petelle B, Vincent G, Meyer B. Le syndrome d'apnée hypopnée obstructive du sommeil. Rev Ortho Dent Fac. 2006;40:177-198.

17. Guilleminault $C$, Pelayo R, Leger D, Clerk A, Bocian RC Recognition of sleep-disordered breathing in children. Pediatrics 1996;98:871-882.

18. Li K, Riley R, Powel N, Hester J. Skeletal expansion by gradual intraoral distraction osteogenesis for the treatment of obstructive sleep apnea. Operative Techniques in Otolaryngology-Head and Neck Surgery. 2002;13:119-122.

19. Madani M, Madani F. Epidemiology, pathophysiology and clinical features of obstructive sleep apnea. Oral Maxillofac. Surg. Clin. N. Am. 2009;21(4):369-75.

20. Patil SP, Schneider H, Schwartz AR, Smith PL. Adult obstructive sleep apnea. Chest. 2007;132:325-337. 
21. Pessey J-J, Lombard L, [title?] EMC-Oto-Rhino-Laryngol. 2001;Article(20-621-A-10):1-15.

22. Peltomäki T, The effect of mode of breathing on cranio-facial growth-revisited, Eur. J. Orthodontics. 2007;29;426-429.

23. Pételle B, Fleury B, Cohen-Lévy J. Traitement chirurgical du syndrome d'apnées du sommeil. Rev. Orthopédie Dento-Faciale. 2009;43(3):317-33.

24. Rees K, Wright A, Keeling JW, Douglas NJ. Facial structure in the sudden infant death syndrome: case control study. Br Med J 1998;317:179-180.

25. Riley RW, Powell NB, Li KK, Troell RJ, Guilleminault C. Surgery and obstructive sleep apnea: long-term clinical outcomes. Otolaryngol-Head Neck Surg Off J Am Acad Otolaryngol-Head Neck Surg. 2000;122(3):415-21.

26. Ryan CF. An approach to treatment of obstructive sleep apnea/hypopnea syndrome including upper airway surgery. Thorax. 2005;60:595-604.

27. Seailles T, Couloigner V, Cohen-Lévy J. Savoir dépister le Syndrome d'Apnées Obstructives du Sommeil (SAOS) de l'enfant. Rev Orthopédie Dento-Faciale. 2009;43(3):261-77.

28. Valiathan M., El H., Hans M. Palomo M. Effects of extraction versus non-extraction treatment on oropharyngeal airway volume. Angle Orthod. 2010;80:1068-1074.

29. Varvarigou V, Dahabreh IJ, Malhotra A, Kales SN. A Review of Genetic Association Studies of Obstructive Sleep Apnea: Field Synopsis and Meta-Analysis. Sleep. 2011;34(11):1461-8.

30. Vecchierini M-F, Laaban J-P, Desjobert M et al. Stratégie thérapeutique du SAHOS intégrant les traitements associés. Rev. Mal. Respir. 2010;27:S166-78.

31. Weitzenblum E, Racineux J-L. Syndrome d'apnées obstructives du sommeil. Paris : Masson; 2004.

32. Young T, Peppard PE, Taheri S. Excess weight and sleep-disordered breathing J. Appl. Physiol. 2005;99(4):1592-1599.

33. Zucconi M, Caprioglio A, Calori G, et. al. Craniofacial modifications in children with habitual snoring and obstructive sleep apnoea : a case-control study. Eur Respir J 1999;13:411-417. 